
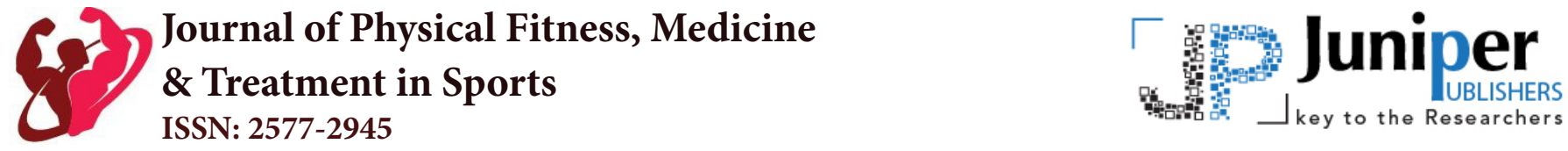

Review Article

Volume 3 Issue 5 - May 2018

\title{
Sport as a Myth
}

\author{
Klimov Mikhail Yuruevich* \\ Department of physical education, Altai state University, Russia
}

Submission: May 07, 2018; Published: May 17, 2018

*Corresponding author: Klimov Mikhail Yuruevich, Associate Professor, Department of physical education, Altai state University, Russia, Tel: 89039957808; Email: michailklimov@yandex.ru

\section{Introduction}

Sport is a part of a unified semiotic sphere. The semiotic sphere is subject to the same rules and laws that are inherent to the entire culture. Ideas, opinions, beliefs and customs that exist in the semiotic space of sports can be defined as an ideology, Eco said: "Ideology-all the things one way or another sign of the addressee and the social group to which it belongs, its psychological expectations all his intellectual skills, experience, ethical principles" [1]. When the fan (addressee), comes to the stadium, opens a sports newspaper or listens to the reportage, he plunges into the semiotic space of sport; It projects in this space the ideology of cultural space, in the atmosphere which was he raised and grew up. The sports text with sport ideology forms a special form of sports ideology that we call sports mythological thinking. At the heart of sport are real numbers and facts: kilograms, meters, seconds, the specific results of matches and duels. And still, sport is susceptible to mythologizing, hardly more than other cultural phenomena.

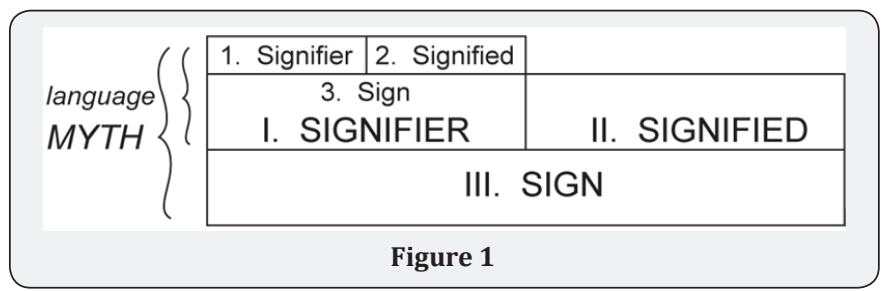

Rolan Bart was the first who explored the Nature of the modern myth. He considered the myth as a semiological system. Barthes writes: «Mythology is part of symptomatology the same time as science formal science and ideology, historical; She is studying ideas furnished» [2]. The semiotic triangle is at the heart of the construction of the myth (Figure 1). Barthes upgrades over him another triangle considering the actual myth secondary semiological system where a sign (that is, the result of the Association of the concept and the acoustic image) the first system is the only meaning the second system: This implies that in myth there are two semiological systems, one of which is staggered in relation to the other: a linguistic system, the language (or the modes of representation which are assimilated to it), which Barthes call the language-object, because it is the language which myth gets hold of in order to build its own system; and myth itself, named Barthes meta language, because it is a second language, in which one speaks about the first.

We accept the structure builds the myth, though in General his concept is not free from controversy. Barthes idolizes and politicized the myth. In an effort to refute the Myth and reality of the true meaning of return, Barthes (as genuine myth) creates a new myth: "revolution creates the world and its language, its language is functionally involved in this creative act. Myth and revolution of mutually exclusive" [2]. Barthes collapses on a myth because it turns history into nature, replaces reality an illusion: "the function of myth is to decimate reality; myth-it is literally a continuous bleeding, the flowing, evaporation of meaning, in short, a palpable lack of it" [2].

It seems to us that, on the contrary-the return of the object "genuine" entity means in fact it desensitization. Objects in this reality represent themselves: they stop something mean, symbolize, and indicate that there is to be meaningful. Mackowskaya said that sport in this reality "not telling" nothing and "does not reflect". The sport does not need such a reality; he creates his reality, his nature. The same reality and myth. Losev stressed: "there is no Myth being perfect, but it is vital and is perceived, the real reality and flesh, to animals flesh reality [3]. The myth is necessary, it fills sports particular historic and dramatic turns in the Game play and presentation, attaches to sports text attraction and tension.

Mythologizing sports text is inherent and inevitable phenomenon in semiotic sport space. It is predetermined by the specificity of sports semiotic space. Actually at the primary stage of perception of visual distortion could arise in Games Sports text and its mythologizing. This happens when the Visual picture wrestling superimposed verbal accompaniment of the television commentator. The most impartially comment acts as a subjective retelling of the objective process-it (comment) is content to the form (Visual text). This text is not the same as the text already contains all the Visual and signs sports myth. When retelling of the Visual sports text and its translation in the written text of the birth of sports myth predetermined structure secondary semiotic system according to Barthes. The writer Gaston Durnez 
notes that in sports journalism, as in theology, "the main thing is to be able to interpret everything in the right light" [4].

Table 1: The Structure of the Sports Myth.

\begin{tabular}{|c|c|}
\hline S. No & Structure of the Sports Myth \\
\hline 1 & The Sports Text \\
\hline 2 & Mythological Consciousness \\
\hline 3 & The Sports Myth \\
\hline
\end{tabular}

We can imagine structure of the sports myth by Barthes's formula: The mythical consciousness is not an abstract category, it is a semiotic view, equally real, like all semiotic space. Losev emphasized: "For the mythical consciousness per se is neither a myth nor a fabulous being, nor even just transcendent (Table 1). This is the most real and alive the most direct and even sensual Genesis" [3]. Barthes scheme corresponds to our understanding of the landmark structure: here sports text appears as a form, the mythical consciousness fills its content, and the sports myth embodied meaning or value that we put into picture of Sports Games.

Mythological sports text exists only within the framework of semiotic space as sport operates signs and language of sport. Despite the huge variety of sports and sports competitions can be reduced any texts to multiple groups, expressing the common mythological subjects. These plots correspond on the universe as a whole. Lothman distributed this rule on the entire culture: "The law-forming Center of cultures, genetically upstream to the original mythological core, reconstructs the world as totally ordered, with a single story and highest sense" [5]. The same orderliness and usefulness has the sports world-semiotic space sports.

Sport, as a semiotic system is in constant motion and change. The changes concern both the sports text: continuous changing game episodes (code), and paintings of semiotic space-one match replaces another, the competition is replaced by competition, with the end of one sports season begins next. In semiotic space sport happens thus continuous circular motion of events and accidents. A unified semantic chain of such events (a match or Championship) forms the story. The plot is built from a number of successive texts at a certain time interval.

Lothman describes two typological forms of plot lines, corresponding to the two types of time: cyclic and linear. Circular time dominates in archaic cultures. The first feature of the texts, created according to the laws of circular time is the lack of categories beginning and end: the text is conceived as some continuously repeated device synchronized with cyclical processes of nature. Human life here was not regarded as a linear line, between birth and death, and constantly repeating cycle. Another feature associated with the cycle, is the trend towards unconditional identification of various characters. This means that these cycles, both day and year, a circular chain of births and dying person or God are mutually homeomorphic. Developments in text producer devices of this kind are intended as inherent in a certain position and cycle originally recurring. Regularity of replay makes them not excesses and opportunity, and the law, is inherent in the world. Cyclic text producer device typologically confronts another text building, organized in accordance with a linear temporal movement and fixation not regularities and anomalies. If the first tests, principle here is the case. Historically the first mechanism developed law believesand analog texts as sacred and scientific nature of the other historical texts, chronicles and annals. Lothman emphasizes the different fundamentally pragmatic nature of these age-old opposite types of texts: "Myth is always talking about me." News "joke tell a different story. First organizes the world of the listener, the second ads interesting details to his knowledge of this world "[5].

A sport is the interaction and combination of these two types of texts. Along with the cyclical change of competitions in sports category are present necessarily start and end. This inherent quality of sports: all sports all competition must begin with an equal position of all participants; the end of such competition must necessarily determine the winner. Sports semiotic space can be divided into different time cycles: gaming, competitive, seasonal and Olympic.

a) A game time lapse is one match race, the sprint, the boxing match is a primary semantic unit of competition, between the beginning and end of which expands the Visual sports text.

b) Competitive cycle combines Games draw a single Championship (or Cup). The formula of the competition can be the most various: pie (all commands or the participants play each with each other in a circle), Cup (teams form pairs, loser eliminated, winner goes on), mixed (in the first stage, teams play round, then knock-out). If any formula all teams or the participants start from scratch. The winner is the participant who gets the highest conditional points or WINS final game.

c) Coincides with the annual seasonal cycle, but is based on different principles than the natural seasons. At the beginning of this cycle required preparatory period when a team or athlete to lay the necessary foundation of physical training. This is followed by a competitive period: a succession of minor competitions allows you to dial "form" to the main start of the season. Finishes season usually recovery period.

d) Olympic cycle is similar to the seasonal only is four years. The cycle starts with the season following the previous Olympics, ends with a performance at the Olympics. All the intermediate seasons are treated as acquisition of competitive experience, the improvement of the physical, psychological, technical and tactical qualities of an athlete to achieve the best results in the most important competitionsthe Olympics. 
There is another time cycle, equal career individual athlete. This cycle we call "life". «Sport life» in a concise and concentrated form resembles a normal way of life: a man makes the first steps in sports (born as an athlete), learning, trying to realize himself, succeeds and fails. Withdrawal from the sport fully complies with the "death" of an athlete: he leaves the semiotic space sports, ceases to be mentioned in gaming protocols and sports news. For many former athletes only "sporting life" and appear to be present. Vlasov describes leaving the big-time sports as a tragedy: "Great athletes get to the title as a reward for decades of labor sonorous prefix" ex ". The former is often this refers to the entire life, because all life after probably fictional alien and that to "ex"- the only worthwhile. After all, for most of them sport-everything in life, following it-worries, uncertainty, often need. And instead of veneration is indifference, impersonality, fading. Of this fame, reverence is in the basement of oblivion of silenceaceptaste. Instead of huge relevance to all-suddenly the worthlessness and unsuitability to another life "[6].

All competitive sport cycles contain categories of the start and the end. These categories show the most prominent role in the Game. Before the Game (whether it is a football game, athletics or wrestling match) ritual of representation of athletes is obligatory. The greater the event is, the more solemnly and magnificently looks ritual. Prelaunch ritual reflects the equality of the athletes (it is necessarily to represent all the contestants). If the Game coincides with the completion of the competition and reveals the winner, another ritual is mandatory-champion`s celebration. Awardees ascend the podium, the winner, in whose honor the national anthem sounds, stands on the very top step. This ritual expresses another sport's law: "survival of the fittest" and "the winner gets all" (only one receives the title of champion and all the honor associated with it). Mechkovskaya carries ritual act to the first semiotic processes that shaped the mythological ideas of primitive people, and the ritual to the ancient of social semiotics, from which evolved (spun off) such semiotics as art, religion, sound language of words, as well as many subsystems in the semiotics of behaviour [7].

The ritual included in the text of the sport, reflects the essence of competition and semantically reproduces the entire sports world order in a symbolic way: the equality and unity of the beginning, the triumph of justice and the hierarchy at the end. It brings together a microcosm of sports with ancient mythologized notions and rites. The ritual in sports is not included in the rules of the competition - a set of regulated activities, the violation of which is punished severely ("written law" system). The ritual has developed as a traditional ceremony that reflects the essence of sport: equality before the law, fair play and victory of the most worthy. In team sports before the match (as a symbol of respect for the opponent) and after its completion (the appreciation of honest and decent game) teams shake hands. Disclaimer handshake ceremony is a demonstration of hostility to the opponent, as well as opposition to the fairness of the final result.
With the ritual a number of rules exist which are not recorded in official documents, but are an important part of the overall system of sports culture. These "unwritten laws" go back to taboo-magical combination of rules prescribing specific behaviour. In sports, the taboo corresponds to the concept of fair play (fair game). Fair play can be seen as signs of a visual sport text reflecting the moral values of a sporting event, the moral experience of sport's culture. Along with the temporal categories of beginning and end continuous cycle running time exists in the sport. It concerns the competition. Any competition is presented as a complete life cycle. Teams and athletes come to it full of strength and desire to win. End of the competition means the termination of the cycle, "death" in this time interval.

The theme of death in sports is quite popular and is expressed in the appropriate terminology. The winning team is «killing time» in an effort to keep the winning score. In hockey, in «knock-out» games, if the main time of the match ends with a tie score, the extra time is given to the moment when one of the teams scores the winning goal. This situation is called "sudden death." "Group of Death" is called the preliminary group, where as a result of the draw are very strong teams, with no clear leaders and outsiders.

Fans along with athletes go through two states of a symbolic "death": "happy ending" and "tragic end", respectively, if the team (or player) won or lost. In case of victory, the entire text of Games becomes a space where all together - the fans and the team - are strong and happy. Another matter is a defeat. But here, the negative feelings and negative emotions are inevitably accompanied by hope: favorite team will overcome destiny and win the next game or the championship. A team has another immortal substance in sports. As a rule, they appeared before the birth of the modern fan and every true fan firmly believe that they will last forever - even after his death. Genesis of a team really excels timeframe of a single generation. A "sport's lifetime " is even shorter. This only adds to the feeling of eternity command: novice player becomes a veteran of sports and ends the way in sports, he is replaced by other players, they are replaced by the next generation, and it always will be. Lotman believed such time experience as an essential feature of mythological consciousness: "Mythological consciousness is characterized by closed-cyclical attitude to time. The annual cycle is similar to the daily human life - plant, the law of birth dying - revival dominates the whole "[5].

Any competition presupposes the existence of an enemy. During the confrontation the athletes watch the crowd. They are divided into two groups, each of which identifies itself with one of the contestants. This opposition is signified as "your / someone else." Possible oppositions can be perceived as a "righteous / sinful", "good / bad". All that is "his" acts as a "native", "foreign" seems "enemy." From a sports match is presented as a struggle of "good" from "evil." "His" athletes endowed with positive moral features, they confront the "other" negative heroes. The storyline fight of the hero in a hostile environment has a match in many 
mythological versions: Odysseus in Cyclops ' cave, Prince Ivan in the Kingdom of Koshchey, Siegfried in the Lair of the Dragon. Often mythological narrative is not limited to a duel and the plot unfolds in a perilous journey in overcoming various obstacles on the road to the goal we aspire: the return of Odysseus, the Argonauts, epic Sadko, the way Ilya Muromets in Kiev. In sports the team must play with all participants when circular formula Championship exists. Successive away matches "mythological" players and fans experienced as moving across geographic space, inhabited by hostile tribes. For the ultimate victory in the championship team needs to win or finish in a draw most guest matches-that is, to pass through all the dangers of the long journey.

Sports myths, to one extent or another, preserved remnants of ancient mythological views rooted in primitive culture. One of the essential characters of major world competitions of the Olympic Games, the Universiades (student games), FIFA World Cup and other, less significant, is the presence of an animal mascot. The host country chooses the animal, embodying the characteristics of national spirit. All of these mascots are nothing more than a manifestation of totemism, one of the most sustainable mythological beliefs.

Totemism in sports gets the most various incarnations. To the greatest extent it refers to African sport, where still very strong tradition of primitive culture. Here many teams officially there are posts of wizards. All African football teams have their own informal name, the vast majority of which goes back to the cult of animals, revered in this country: Côte d'Ivoire - «elephants», «Super eagles» Nigeria, Cameroon-"Invincible lions", TunisiaCarthage Eagles.

Similar names are not uncommon even in more civilized countries. Here such a tradition is largely an artificial one as a result of studying the market and the prospects for commercial use of the name, so the animals include the official name of the team. In the National Hockey League team plays "San Jose Sharks", "Pittsburgh Penguins", "Florida Panthers", "Anaheim Mighty Ducks". No sharks, penguins and panthers inhabit listed cities, while the latter moniker announces affiliation of corporation "Walt Disney", which produces cartoons, where characters- duck are popular. There are such teams as team the "Chicago Bulls", "Indiana Pacers", "Atlanta Hawks", "Minnesota Timberwolves" in the National Basketball Association. The artificiality of such names does not interfere with the teams ' history and traditions associated with these beasts. All the more so, there are special commands, the services responsible for the popularization and promotion of their own brand. Fans associate the command with the most favorite images the positive qualities of their animals (power, strength, swiftness, fearlessness), and journalists use as so hackneyed cliches ("have trampled, escaped, soared-bitten, flew").

Assigning nicknames is a sustained and widespread phenomenon in sports mythological consciousness. Nicknames are not only given the teams but also the individual outstanding athletes. It is not uncommon for nicknames to displace names. This is typical for Brazil, where soccer has evolved into a national religion. Pele, Garrincha, Ronaldinho-all these nicknames these same names internationally known players knows very few of the fans. Also given soundings and loud epithets, stressing the grandeur and superiority tagged with athletes. In addition to positive and proud titles in sport there are hurtful, derogatory nicknames, which the hostile fan groupings give the opponents. In this case, in semiotic space of sport processes similar to controversial phenomena in cross-cultural text box pass. The name, which is "awarded" contender is assigned and is renamed, retaining the old form. Pejorative moniker given to the opponent is appropriated by and included in "your" language, acquiring a positive assessment.

So, in The Russian Football Premier League, the most intransigent team CSKA and Spartak are long given offensive, in terms of opponents, nicknames: "horses", "stable" (CSKA) and meat (Spartak Moscow). Accordingly, these nicknames have moved to all fans of these commands. Without going into the etymology of names, it should be noted that lately fans of these clubs willing to call themselves former "shameful" as previously advanced as profanity in the mouths of opponents. Naturally, this has changed meaning in such a name. If "enemies" see "horses" as something lower (compared with the car), dirty (horses-dung) and silly (senseless legwork); the "Army" mean the opposite: something fast (rapid running horse), powerful (trample enemy by hooves) and beautiful (the ancient worship of the individual towards the horse article). The semantic range of nicknames of "Spartak" is not so wide. For opponents meat is a product of consumption, what is eaten (sacred eating the enemy). For "Spartak," "meat" is strength and power, proteinsource of life (as opposed to totally vegetarianism). In this regard, we can mention the player's of Spartak Sychev outright act, which, celebrating scored goal, pulled off his t-shirt in 2002 year. Under it there was another t-shirt with the inscription: "who are we? - "meat," which caused an explosion of delight in the stands, filled in with fans of FC Spartak Moscow.

Another ancient belief, embodied in the sport's mythological consciousness is fetishism. Fetishism-the worship of inanimate objects and empowerment them supernatural power in sports acquires its mythological embodiment. Here for fan fetish becomes only a subject related to your favorite team or athlete. Sport is a fertile ground for fetishization, space, filled with a huge number of "significant" items. Nothing compares with the sport by the number of autographs, distributed in this sphere. Autograph symbolizes a part of Idol; everyone strives to get together with him force, luck and a winning spirit, embowering Idol. Any object to which worshiped athlete touched, can turn into a fetish. Worship your favorite team covers all items bearing its insignia. Each club has its own emblem (coat of arms), which usually depicts founded, departmental or geographical (or national) affiliation, and other characters, consecrated in history 
and tradition. It is also binding flag, painted in the color gamut of gaming, which preserves the commands form a constant view of the founding of the Club. Color symbolism often becomes part of the nicknames most popular teams: "the Red Devils" (quite a common name teams wearing red uniforms-Belgium, Liverpool, Manchester United), blue (Chelsea), "Azzurrini" ("Blue Squadron"-Italy), the "Canaries" ("Nantes"-from yellow forms), "white-blue" (Dynamo), the «red-white» (Spartak Moscow). Superstition is quite widespread among athletes. Here the sequence of various shapes becomes fetish kind of superstitions. During the period of responsible gaming for half the teams on both sides appears in the nebritom form. The coach would be "happy" coat or suit, bringing victory, until the team loses. Many players go onto the field strongly with some legs, each, moreover, has its own rite, "providing" good luck. In the NHL, when the rookie scored his first goal, either veteran differs in particular Jubilee times, the judge stops the game and hands over the perpetrators of celebration commemorative puck.

American psychologist $\mathrm{R}$ Singer considers superstition peculiar ritual athletes conduct or action, regularly committed in specific situations. It is assumed that it increases the probability of winning, leads to mental tranquility, confidence, or at least to achieve the best result in this situation. Singer Associates superstitious behavior with the placebo effect: "Superstition can be exceptionally strong (like any placebo) tool to improve performance, especially at the gullible and suggestible people. If you are superstitious actions not supported by success, they usually stop. Instead, they can be adopted by other ritual-like new hope or a desperate step [8]. Well, then can be seen as a placebo and religion-as a strong and reliable tool for maintaining mental health.

Sport is inconceivable without a numerical component. Along with the corporality, numbers are included in the substantial nature of the sport. Numbers form the game semiotic space, fill the text with the visual sports content and express the value of the result of the Game. The numerical symbolism in semiotic sports space appears as one of the sides of sports mythological consciousness embodies the hypostasis of the sports myth. Novalis said: "It is very likely that in nature, as in history, there is a wonderful mysticism of numbers. Isn't everything full of values, symmetry, and unusual relationship?" [9]. Numerical symbols of the sport dates back to the ancient mythological tradition, gifting the number with magical functions. Troitsky says: "The antique number is always mentioned, individually significant, and even life- saving"[10]. The transformation of sport text into sport myth already starts at the stage of statistical fixing of any sporting event begins. The technical protocol of the Game, which is a collection of "bare" figures and names, not burdened with extraneous comments, starts filling with mythological content, resulting from the magical properties of numbers.

The necessary illustration of any sporting event is a statistical table showing the current performances of teams or sportsmen.
The teams in the table are in accordance with the successes achieved: the clubs with the highest number of points occupy the first lines, then down in descending order. Moving among the results of this table is experienced by sportsmen and their fans as a mythological journey. Unlike the mythological wanderings in the geographic space, here the journey is performed inside the numerical symbolic space. The table appears as a semiotic space, oriented vertically and has two opposing poles. This construction corresponds to common cosmological ideas, building the opposition for up/down, as a contradistinction of heaven and hell. Teams aspiring to win are at the top of the table- they are drawn to the light, life, happiness. As a result, the best teams are included into the European cups -thus they extend the season (life), meet with the best clubs in the world (celestials).They are in the limelight and receive huge fees for participating in these tournaments. Such teams are praised by all press, their fans rejoice, they get material benefits in the form of various prizes and bonuses. At the bottom of the table- complete opposition. The popular expression for such teams: "the struggle for survival". Here reigns despondency, gloom, despair, and faint hope for rescue. The clubs, ranked last drop out of relegation (are cast into hell). They disappear from this reality- from the pages of the leading sports newspapers and television programs.

Numerical component of the sports text creates the necessary conditions for the formation of a sports myth. The number increases the impact of the sports myth, gives it scope and depth, and stresses the importance of the event. The numeric hypostasis of sporting feat is a world record. The numbers, marking a certain time, distance or weight, express the limit of human capabilities. And here is a sportsman, surpassing all who live and lived before. He crosses the line of reality, striding over the edge, which does not look by mankind, where nobody ever was. Such actions can be done only by few: Orpheus, Hercules, Odysseus. The sportsman, who set a world record is turned from an ordinary person to a hero.

Here's how the American press wrote about Jim Ryan, who at 19 years old become the world record holder in running for mile: "Ryan is a man, who combines all the features of a hero"; "It was incredible. Ryan is so great... the best of the greats. This runner is a physiological phenomenon"; "Strong fire is burning under the quiet good-looking young Jim Ryan, and it is as strong as in any hero, known for the world" [11].

Among the world records there are special ones that stand out from the general series, marking a milestone, which for a long time was considered insurmountable. These magic numbers are required to be "round" ones. In weightlifting this barrier was $600 \mathrm{~kg}$ in the triathlon and $200 \mathrm{~kg}$ in clean and jerk weightlifting in the heaviest weight category. In athletics, almost each type has a magical barrier: the 100 meters- distance running - faster than 10 seconds (11 seconds for women), the 200 metersdistance running - faster than 20 seconds (22 for women), one mile- distance running (1609m) -faster than 4 minutes, long 
jump -8 meters, pole vaulting- 6 meters, shot put $-20 \mathrm{~m}$, javelin - $100 \mathrm{~m}$, etc. The sportsmen, who first overcome such barriers, are all included into the historical records. Bob Beamon after setting up his fantastic record in long jump, looked calmly at the number of " $890 \mathrm{~cm}$ ", which appeared on the scoreboard, while the whole stadium was going crazy. It was only when a teammate transformed the result into feet; Beamon flopped down on his knees, buried his face in his hands and began to shake all over in hysterics. The fact that in America (where commonly used feet and inches) "28 feet" $(8,53)$ was raved about for a long time. He was adored, and he was approached, but very slowly, and the last world record that was achieved did not reach up to 27 and a half feet. But Beamon threw at one fell swoop the number " 28 " to the dustbin of history: his result was 29 feet and 2.5 inches. Since then, the word "Beamonesque" entered the lexicon of American sports. It corresponds to the achievement, so much greater than all the previous ones, that it cannot be classified and served as a benchmark for comparison with anything else.

In those sports where world records are not fixed (sports games, combat sport, figure skating, and so on.) there are informal records that have great importance for these types of sports. Scrupulously taken into account, which scored the greatest number of goals (goals, points) during the match, the championship season, through the whole career. Who won the highest number of medals, won victories (consecutive and total), spent most games or seasons, etc.

Sport numerology includes few numbers with a significant, sacred character in the semiotic space of sport. First of all, it is the monad. Its value is expressed not in quantitative but in qualitative filling: the first in the sport- it is a winner, a champion. In quantitative terms, a one- time success in the sport is more likely considered as a normal and even occasional, not logical one.

The triad is the most widely used in sports numerology. This goes back to the worship of cultural tradition, which considers the number three as a sacred and divine. Only three winners are awarded at each competition, forming a "victory podium". Threetime success in sport is noted as unusual, an outstanding event. In various sports triple achievement is called "hatter" (or hattrick). This name came from hockey, when hockey player scored three goals during one of the matches. Fans delighted ice pelted their hats (a hat-trick - the trick with hats). In basketball there is its own designation of triple success - "triple-double". This is when the basketball player in three markers (totally there are five of them: points scored, assists, ball catch up and blocked shots of the opponent) get more than ten points. Champions in most sports are awarded the challenge cup. According to the rules of the tournament, a sportsman or a team, winning three times in one competition, saves this cup for everlasting storage.

Another significant number in sports numerology is four. It has its own name- "poker". A tennis player who won during one and the same year the four most prestigious tournaments: the Open Championships of Australia, France Open, England Open, or the United States Open, becomes the owner of "Grand Slam". Hence, these events became known as the Grand Slam tournaments. There are no special names for numbers more than four.

The anniversary, "round" numbers has great importance in the sports numerology: 100, 200, etc. In the Russian football there is a symbolic club " 100 ", which includes players scored 100 or more goals. In hockey, such a club unites scorers who have scored 1000 or more points (goals + scoring passes). There is a certain club "100" for goalkeepers (which played an appropriate number of "clean sheet" matches). Coaches, who gained 100, 200 and even 1000 victories are also marked.

Multiple sports champions occupy a special place in the mythological sport consciousness. They are credited with unique properties that allow achieving permanent superiority over the rivals. This is a so-called "killer instinct": the pursuit of a sportsman to win at any price and prevail over rivals. Multiple champions differentiate themselves from other sportsmen; their achievements go back to the mythological interpretation of heroism and heroic deeds. Sports heroes are one up on not only ordinary people and "ordinary" sportsmen, but on "ordinary" champions. They are surrounded by the same aura of grandeur and invincibility, like Perseus, Achilles, Ajax, Bellerophon, Lancelot, Roland, Ilya Muromets.

Multiple victories and good results make statistical regularity and numerical order. This is opposed to an accident and wonder. Belief in miracles is an inherent property of the mythological consciousness. Losev emphasized: "The Miracle is not a violation of the laws of nature. No violation of the laws of nature is a miracle, but, rather the establishment and justification of their comprehension. From the point of view of mythical consciousness a miracle that is an establishment and a manifestation of genuine, truly inviolable laws of nature" [3]. Goliath came out to fight, armed even a statistical advantage: great size and strength, a great experience fights and victories ("multiple champions") came out for him. David had only dexterity in possession of a sling, backed by determination and will to win. A miracle happened - the giant appeared layed down.

The semiotic sports a miracle contradicts a number, denies pattern statistics. Manifestations of a miracle in sport are not so rare. When the competition favorite, having a world record and the best result of the season, suffered an unexpected defeat from the debutant; or a football team losing hopelessly $-0: 3$, suddenly transformed, scoring four goals and wins - then, they say about a miracle. Fans always believe in miracles. So, sport is great because it gives such hope and opportunity for its implementation: the rivals face the competition on equal terms and the old titles and records do not play any role here. Losev stated: "In addition to the logical and aesthetic expediency there is mythical expediency and that it is just a miracle" [3]. 
At the Winter Olympic Games of 1980 in Lake Placid, the USA Team won 6 gold medals. Five of them were won by one and the same person-speed skater Eric Heiden. His achievement is unique, not only in terms of statistics (he still remain the only athlete to win all kinds of skating programs), but also in terms of physiology - Hayden was the fastest in short and long distance as well (they require a different mechanism of power supply). The sixth gold medal was brought by the USA hockey team, which won the decisive match of the Soviet team. Statistically, such successes are incomparable: One person has won five medals, and twenty -only the one. Meanwhile, America forgot Hayden in two years, but the hockey players are still famous and praise so far - in Hollywood a feature film, to mark the $25^{\text {th }}$ anniversary of "Great Victory", was filmed, which is called: "The Miracle on Ice". This happens not only because hockey is more popular than skates in America. Then, the Soviet skaters did not star and were not serious contenders for Hayden. In an era of sharp ideological and political confrontation, the USA hockey team not only won the team of the USSR, which was considered as a strong and invincible. In the eyes of America it looked like a triumph of "democracy" over "The Evil Empire". The most popular sports magazine in America "Sports Illustrated" put the USA hockey team in Lake Placid in the first place in the list of the greatest event in American sports.

Numerical symbols of sport continue myth poetical tradition that focuses on the qualitative and quantitative assessment of the number. Similar trends have been observed in all the cultural space. Toporov wrote: "The archaic representation of the number continues to live in the modern artistic consciousness; moreover, they are transformed and evolve, again and again, serving as the starting material for the construction of new myth poetical concepts and images" [12]. Thus, sports mythology continues the mythological tradition and dates back to a single mythological core, which reflects the view of the universe as a whole.

\section{References}

1. Eco U (2004) Otsutstvuiaschaia structura. Vvedenie v semiologiu- St Petersburg. Simposium, Russia, pp. 544.

2. Bart R (1994) Isbrannhie raboty: Semiotica Poetica. Progress, Russia pp. 616.

3. Losev AF (1994) Myth - chislo - suschnost. M Mhysl, Russia, pp.919.

4. Vinokurov (1981) VI Schag k istine. Phiscultura I sport, Russia, pp. 192.

5. Lotman YM (2000) Semiosfera. Iscusstvo - SPb, Russia, pp. 704.

6. Vlasov YP (1995) Spravedlivost sily. NKI, Russia, pp. 597.

7. Mechkovskaja NB (2004) Semiotica: Iashik. Priroda, Cultura Cours lecthii. Academia, Russia, pp. 432.

8. Singer RN (1980) Myth I realnost v psihologii sporta. Phiscultura I sport, Russia, pp. 152.

9. (2005) Encyclopedia Symbolov, snacov, ehmblem. Exmo SPb Midgard, Russia, pp. 608.

10. Troitsky VP (1994) 0 smhysle chisel - chislo - suschnost. Mhysl, Russia, pp. 894-904.

11. Nelson K (1974) Jim Ryan - Recordsmen is Wichita. Phiscultura I sport, Russia, pp. 192.

12. Toporov VN (1992) Chisla: Mythy narodov mira. Rosencyclopedia, Russia, 2: 629-631.

\section{Your next submission with Juniper Publishers will reach you the below assets}

- Quality Editorial service

- Swift Peer Review

- Reprints availability

- E-prints Service

- Manuscript Podcast for convenient understanding

- Global attainment for your research

- Manuscript accessibility in different formats ( Pdf, E-pub, Full Text, Audio)

- Unceasing customer service

Track the below URL for one-step submission https://juniperpublishers.com/online-submission.php 